\title{
Group Physiotherapy for Treatment of Pelvic Floor Dysfunction: A Consumer's Perspective
}

Rose C. Green

Women's and Children's Hospital, Adelaide, South Australia, roseeriksen33@yahoo.com.au

Follow this and additional works at: https://nsuworks.nova.edu/ijahsp

Part of the Medicine and Health Sciences Commons

\section{Recommended Citation}

Green RC. Group Physiotherapy for Treatment of Pelvic Floor Dysfunction: A Consumer's Perspective. The Internet Journal of Allied Health Sciences and Practice. 2021 Jan 01;19(2), Article 11.

This Manuscript is brought to you for free and open access by the College of Health Care Sciences at NSUWorks. It has been accepted for inclusion in Internet Journal of Allied Health Sciences and Practice by an authorized editor of NSUWorks. For more information, please contact nsuworks@nova.edu. 


\title{
Group Physiotherapy for Treatment of Pelvic Floor Dysfunction: A Consumer's Perspective
}

\begin{abstract}
Introduction: Level 1 grade A evidence exists to support physiotherapy as a first line treatment of women with stress urinary incontinence and pelvic organ prolapse (POP). A novel way to provide care for women with pelvic floor dysfunction in a tertiary hospital setting is to mandate attendance at an introductory group education session prior to offering an individual physiotherapy consultation. There is minimal research to date examining the consumer perspective of group physiotherapy for treatment of pelvic floor dysfunction. This study aims to evaluate the consumer experience with a view to determining if this model of care meets the needs and expectations of the consumer. Objective: To evaluate the consumer perspective of an educational and practical pelvic floor class prior to offering an individual physiotherapy appointment for women with pelvic floor dysfunction. Method: Over a 6-month period, 39 women completed a voluntary, anonymous survey to evaluate their experience of attending a physiotherapy pelvic floor class. Results: Respondents reported that the information delivered was appropriate, relevant, and engaging and felt more informed and less alone in their symptoms after attending the pelvic floor class. Women reported that they had received the necessary education and practical skills required to begin implementing practical changes that addressed their pelvic floor dysfunction. Conclusion: By providing a consistent, informative, and practical group session for women referred with pelvic floor dysfunction as a baseline entry point to individual care, treatment can be commenced that is acceptable to the consumer. The acceptability of this method of service delivery serves as a basis for further important research evaluating the efficiency and effectiveness of group physiotherapy treatment.
\end{abstract}

\section{Author Bio(s)}

Rose Green is a senior physiotherapist working in the women's Physiotherapy department of the women's and children's hospital Adelaide, South Australia. She holds a post graduate certificate in in Pelvic Floor Physiotherapy. 


\title{
IIJAHSP \\ The Internet Joumnal of Allied Health Sciences and Practice \\ Dedicated to allied health professional practice and education
}

Vol. 19 No. 2 ISSN 1540-580X

\section{Group Physiotherapy for Treatment of Pelvic Floor Dysfunction: A Consumer's Perspective}

\author{
Rose C. Green \\ Women's and Children's Hospital
}

Australia

\begin{abstract}
Introduction: Level 1 grade A evidence exists to support physiotherapy as a first line treatment of women with stress urinary incontinence and pelvic organ prolapse (POP). A novel way to provide care for women with pelvic floor dysfunction in a tertiary hospital setting is to mandate attendance at an introductory group education session prior to offering an individual physiotherapy consultation. There is minimal research to date examining the consumer perspective of group physiotherapy for treatment of pelvic floor dysfunction. This study aims to evaluate the consumer experience with a view to determining if this model of care meets the needs and expectations of the consumer. Objective: To evaluate the consumer perspective of an educational and practical pelvic floor class prior to offering an individual physiotherapy appointment for women with pelvic floor dysfunction. Method: Over a 6-month period, 39 women completed a voluntary, anonymous survey to evaluate their experience of attending a physiotherapy pelvic floor class. Results: Respondents reported that the information delivered was appropriate, relevant, and engaging and felt more informed and less alone in their symptoms after attending the pelvic floor class. Women reported that they had received the necessary education and practical skills required to begin implementing practical changes that addressed their pelvic floor dysfunction. Conclusion: By providing a consistent, informative, and practical group session for women referred with pelvic floor dysfunction as a baseline entry point to individual care, treatment can be commenced that is acceptable to the consumer. The acceptability of this method of service delivery serves as a basis for further important research evaluating the efficiency and effectiveness of group physiotherapy treatment.
\end{abstract}

Keywords: pelvic floor dysfunction, pelvic floor, physiotherapy, class 


\section{INTRODUCTION}

Pelvic floor dysfunction, including incontinence and pelvic organ prolapse, is not only a personal burden for many Australian women; it also carries a considerable financial cost. In 2010, total health system expenditure on incontinence in the Australian population was estimated at $\$ 271$ million, and this was projected to rise to $\$ 450$ million by $2020.1^{1}$ The total economic cost of incontinence in 2010 was estimated to be approximately $\$ 66.7$ billion or $\$ 14,021$ per person with incontinence. ${ }^{1}$ It is internationally accepted that conservative physiotherapy should be the first line of treatment offered to women with incontinence and/or pelvic organ prolapse symptoms, with high level evidence to support pelvic floor muscle strength training for women with urinary incontinence and pelvic organ prolapse. ${ }^{2-4}$ In a tertiary hospital, it is necessary to provide efficient and effective treatment in a manner that meets the consumer's needs whilst following accepted best practice guidelines.

To the author's knowledge, there has been limited research in the field of group education for pelvic floor dysfunction and this study was undertaken to add valuable insight into the consumer experience of such a group. ${ }^{5-7}$ Previous studies have compared group versus individual physiotherapy sessions involving education and exercise for pelvic floor muscle dysfunction and found no difference in clinical outcomes between the groups. ${ }^{5,8}$ High quality research has demonstrated that individual physiotherapy sessions are comparable to group session in terms of positive clinical outcomes, yet few studies have investigated the acceptability to patients of undertaking treatment in a group setting. A systematic literature review by Cook demonstrated that there was insufficient evidence available to adequately assess the efficacy of group treatment for urinary incontinence because of a lack of published evidence, no consistent outcome measures, and differing group formats. ${ }^{9}$ Of the published research, few explored the consumer perspective captured in this study.

In our clinical practice as women's health physiotherapists we provide assessment and treatment for women with symptoms of a diverse range of pelvic floor dysfunction conditions. The aim of this study was to evaluate the pelvic floor class from the consumer perspective immediately at the conclusion of the class and again when they attended their first individual appointment. Previous research has evaluated the effectiveness of physiotherapy intervention for pelvic floor dysfunction, but limited evidence exists to establish whether women find physiotherapy delivered in a group setting appropriately addresses their individual needs. It has been established that the most efficient use of health care funding is one that encompasses a patient centred approach. ${ }^{19}$ By effectively evaluating the consumer's experience of group treatment for pelvic floor dysfunction, we can more appropriately involve patients in decision making relating to their own health care and ultimately improve the quality of our physiotherapy service delivery.

\section{METHODS}

In response to escalating referral numbers and static resources in 2007, a pelvic floor class was implemented prior to offering an individual physiotherapy appointment in an attempt to maximise efficient use of resources and deliver a standardised baseline level of education to consumers accessing the service prior to individual consultation. Since the group session implementation, there has been consistent positive anecdotal verbal feedback from class participants, but no formal evaluation has taken place to date. This study was developed to formally record and analyse the patient experience of the class and potentially provide a basis for further research of this service delivery.

Ethics approval for this study was granted by WCHN Human Research Ethics Committee (audit 1056A/10/2021). Referrals were triaged as per usual inclusion/exclusion criteria into the pelvic floor class, with women included if the referral information was suggestive of incontinence (urinary and/or anal) and/or pelvic organ prolapse symptoms. Women were excluded if there were symptoms suggestive of chronic pelvic pain, they were non-English speaking (requiring an interpreting service), under the age of 18 , or, had a history of significant mental health history that may prohibit group participation. Two questionnaires were developed by the clinician delivering the class based on a literature search of previous studies evaluating group physiotherapy to treat pelvic floor dysfunction. 6,7

The first questionnaire included a combination of statements assessed by the consumers via a Likert scale and a series of free text questions; this was given to the women on completion of the class. Participants were requested to complete the questionnaire in its entirety. Consumers' responses covered the perceived benefit, identified key self-management strategies, and ascertained whether the session met their individual needs. A follow up survey was given to those women who booked into an individual appointment. This free text questionnaire consisted of three questions that asked the women to retrospectively reflect on the perceived benefit of attending the class. Women were asked to reflect on any practical selfmanagement measures they had implemented since attending the class and suggestions for any improvements that could be made to the class.

The key objectives of the group session were to provide consistent education in relation to pelvic floor anatomy, normal bladder and bowel function, and common pelvic floor dysfunction symptoms. Correct pelvic floor muscle (PFM) activation was explained, and participants were subsequently able to practice PFM activation in various positions (lie, sit, and stand). The physiotherapist demonstrated how to contract the PFM under varying levels of stress (cough, squat, sit to stand). 
Pelvic floor classes were run monthly during the study period (October 2018 to April 2019). The participants were advised via letter that an appointment had been made for them to attend a class and that the session would run for approximately 2 hours. Women were offered the opportunity to book individual appointments after session attendance. The same physiotherapist instructed each of the classes and presented a consistent power point presentation and practical exercise component for each class. The presentation covered the anatomy of the pelvic floor (including the use of a 3D pelvic model as a visual aid), education in relation to the different types of incontinence, and a clear explanation of how to perform a correct pelvic floor muscle contraction. Education relating to pelvic organ prolapse (POP) was included and graphical illustrations of the different types of POP and common symptoms of dysfunction discussed. Following the presentation, participants were given the opportunity to ask questions and were then able to practice pelvic floor muscle activation in various positions using props such as exercise mats and a fit balls. The physiotherapist gave appropriate verbal instructions relating to their technique. Once informed consent was obtained, the physiotherapist provided hands on correction of their body position as required.

The participants were given relevant "homework" to complete prior to attendance at their individual appointment (such as a bladder diary) to optimise efficiency of their individual consultation (if needed). The evaluation survey and study information sheet were issued at the conclusion of the session (via hard copy) and the participants were invited to complete the survey prior to leaving. Participants were given the option of filling out the survey anonymously or leaving their contact details if they wished to discuss their feedback. The therapist requested that the participants answer all of the questions. Survey completion was voluntary, and participants were informed that survey completion (or not) would not impact on their current or future care at the hospital. Participants who attended an individual appointment approximately 6 weeks following class attendance were invited to complete an additional questionnaire that asked them to reflect on the class in hindsight, flag any changes in their symptoms, and report any subsequent lifestyle or behaviour modifications they had implemented since attending the class.

\section{RESULTS}

Of the referrals received from the gynaecology department during the study period, 61 women were triaged to a pelvic floor class. Of those triaged to a group session, 39 women attended over 7 sessions (64\% attendance), with the remaining 22 women $(36 \%)$ failing to attend and/or cancelling their session without rebooking. One session was not included due to low numbers $(n=1)$, and one participant's response was not included due to limited English (not identified on referral triage). Class sizes varied between 2 and 9 women. The average time from the referral being received in physiotherapy to a class session being offered to the patient was 33 days. Administrative error resulted in 2 patients waiting for $>60$ days.

The first component of the questionnaire related to how the women felt after they received the letter inviting them to attend the group and the results tabulated, as per Table 1 . The majority of women $(n=27 / 33,81 \%)$ reported that they were worried about their symptoms, but only approximately $1 / 3$ were embarrassed about their condition $(n=13 / 36,36 \%)$. Approximately $1 / 3$ of the women $(n=13 / 37,35 \%$ ) did not feel that they had a good understanding of their condition prior to attending the class. Most of the women felt that they could easily attend the session $(n=28 / 36,78 \%)$, and were comfortable to be placed in a group setting $(n=29 / 38,76 \%)$.

Table1: Responses to questions - perceptions of women prior to attending pelvic floor class.

\begin{tabular}{|c|c|c|c|c|c|}
\hline & $\begin{array}{l}\text { Strongly } \\
\text { agree }\end{array}$ & Agree & Unsure & Disagree & $\begin{array}{l}\text { Strongly } \\
\text { disagree }\end{array}$ \\
\hline $\begin{array}{l}\text { I was embarrassed about my } \\
\text { condition }(n=36)\end{array}$ & $\begin{array}{l}3 \\
(8 \%)\end{array}$ & $\begin{array}{l}10 \\
(27 \%)\end{array}$ & $\begin{array}{l}6 \\
(17 \%)\end{array}$ & $\begin{array}{l}8 \\
(22 \%)\end{array}$ & $\begin{array}{l}9 \\
(25 \%)\end{array}$ \\
\hline $\begin{array}{l}\text { I was worried about my } \\
\text { symptoms }(n=33)\end{array}$ & $\begin{array}{l}8 \\
(24 \%)\end{array}$ & $\begin{array}{l}19 \\
(58 \%)\end{array}$ & $\begin{array}{l}2 \\
(6 \%)\end{array}$ & $\begin{array}{l}3 \\
(9 \%)\end{array}$ & $\begin{array}{l}1 \\
(3 \%)\end{array}$ \\
\hline $\begin{array}{l}\text { I felt I had a good } \\
\text { understanding of my } \\
\text { condition }(n=37)\end{array}$ & $\begin{array}{l}8 \\
(22 \%)\end{array}$ & $\begin{array}{l}16 \\
(43 \%)\end{array}$ & $\begin{array}{l}8 \\
(22 \%)\end{array}$ & $\begin{array}{l}3 \\
(8 \%)\end{array}$ & $\begin{array}{l}2 \\
(5 \%)\end{array}$ \\
\hline $\begin{array}{l}\text { I was feeling happy to be } \\
\text { placed in a group setting } \\
(n=38)\end{array}$ & $\begin{array}{l}10 \\
(26 \%)\end{array}$ & $\begin{array}{l}19 \\
(50 \%)\end{array}$ & $\begin{array}{l}7 \\
(18 \%)\end{array}$ & $\begin{array}{l}1 \\
(3 \%)\end{array}$ & $\begin{array}{l}1 \\
(3 \%)\end{array}$ \\
\hline $\begin{array}{l}\text { I could easily attend the } \\
\text { session booked for me } \\
(n=36)\end{array}$ & $\begin{array}{l}12 \\
(33 \%)\end{array}$ & $\begin{array}{l}16 \\
(44 \%)\end{array}$ & $\begin{array}{l}4 \\
(11 \%)\end{array}$ & $\begin{array}{l}3 \\
(8 \%)\end{array}$ & $\begin{array}{l}1 \\
(3 \%)\end{array}$ \\
\hline
\end{tabular}

The second part of the survey related to how the women felt following the completion of the class with the results summarised in Table 2. All the women $(n=39 / 39,100 \%)$ agreed/strongly agreed that the information was delivered in a manner that was easy to understand, was engaging and well organised, and ran for an appropriate amount of time. Of the participants, 97\% (n 
$=38 / 39)$ felt comfortable in the group setting. All of those who completed the survey $(n=38 / 38,100 \%)$ felt that the presentation was useful, were glad they attended, and could recommend it to others. The majority of the women felt confident that at the completion of the class they could correctly activate their pelvic floor, had a good understanding of the anatomy of the pelvic floor, and felt that they had a good understanding of their condition. The majority of participants felt reassured after attending the class that they were not alone and more than half $(n=24 / 38,63 \%)$ felt less worried about their symptoms.

Table 2. Perceptions of women after attending pelvic floor class.

\begin{tabular}{|c|c|c|c|c|c|}
\hline & $\begin{array}{l}\text { Strongly } \\
\text { agree }\end{array}$ & Agree & Unsure & Disagree & Strongly disagree \\
\hline $\begin{array}{l}\text { The information was delivered } \\
\text { in a way that was easy to } \\
\text { understand } \\
(n=39)\end{array}$ & $\begin{array}{l}27 \\
(69 \%)\end{array}$ & $\begin{array}{l}12 \\
(31 \%)\end{array}$ & & & \\
\hline $\begin{array}{l}\text { The power point presentation } \\
\text { was useful } \\
(n=38)\end{array}$ & $\begin{array}{l}28 \\
(74 \%)\end{array}$ & $\begin{array}{l}10 \\
(26 \%)\end{array}$ & & & \\
\hline $\begin{array}{l}\text { The session went for the right } \\
\text { length of time } \\
(n=36)\end{array}$ & $\begin{array}{l}27 \\
(75 \%)\end{array}$ & $\begin{array}{l}9 \\
(25 \%)\end{array}$ & & & \\
\hline $\begin{array}{l}\text { I feel I have a good } \\
\text { understanding of my condition } \\
(n=39)\end{array}$ & $\begin{array}{l}18 \\
(46 \%)\end{array}$ & $\begin{array}{l}15 \\
(38 \%)\end{array}$ & $\begin{array}{l}5 \\
(13 \%)\end{array}$ & $\begin{array}{l}1 \\
(3 \%)\end{array}$ & \\
\hline $\begin{array}{l}\text { I felt reassured that I was not } \\
\text { alone }(n=38)\end{array}$ & $\begin{array}{l}23 \\
(61 \%)\end{array}$ & $\begin{array}{l}14 \\
(37 \%)\end{array}$ & & $\begin{array}{l}1 \\
(3 \%)\end{array}$ & \\
\hline $\begin{array}{l}\text { I feel less worried about my } \\
\text { symptoms }(n=38)\end{array}$ & $\begin{array}{l}9 \\
(24 \%)\end{array}$ & $\begin{array}{l}15 \\
(39 \%)\end{array}$ & $\begin{array}{l}11 \\
(29 \%)\end{array}$ & $\begin{array}{l}3 \\
(8 \%)\end{array}$ & \\
\hline $\begin{array}{l}\text { This session was well } \\
\text { organised }(n=35)\end{array}$ & $\begin{array}{l}25 \\
(71 \%)\end{array}$ & $\begin{array}{l}10 \\
(29 \%)\end{array}$ & & & \\
\hline $\begin{array}{l}\text { This session was engaging } \\
(n=35)\end{array}$ & $\begin{array}{l}24 \\
(67 \%)\end{array}$ & $\begin{array}{l}11 \\
(31 \%)\end{array}$ & & & \\
\hline $\begin{array}{l}\text { I felt comfortable in the group } \\
(n=39)\end{array}$ & $\begin{array}{l}23 \\
(59 \%)\end{array}$ & $\begin{array}{l}15 \\
(38 \%)\end{array}$ & $\begin{array}{l}1 \\
(3 \%)\end{array}$ & & \\
\hline $\begin{array}{l}\text { I feel I have a good } \\
\text { understanding of the anatomy } \\
\text { of my pelvic floor } \\
(n=39)\end{array}$ & $\begin{array}{l}22 \\
(56 \%)\end{array}$ & $\begin{array}{l}15 \\
(38 \%)\end{array}$ & $\begin{array}{l}2 \\
(5 \%)\end{array}$ & & \\
\hline $\begin{array}{l}\text { I feel confident I can correctly } \\
\text { activate my pelvic floor } \\
\text { muscles } \\
(\mathrm{n}=39)\end{array}$ & $\begin{array}{l}14 \\
(36 \%)\end{array}$ & $\begin{array}{l}14 \\
(36 \%)\end{array}$ & $\begin{array}{l}8 \\
(21 \%)\end{array}$ & $\begin{array}{l}3 \\
(8 \%)\end{array}$ & \\
\hline $\begin{array}{l}\text { I am glad I came today } \\
(n=39)\end{array}$ & $\begin{array}{l}24 \\
(62 \%)\end{array}$ & $\begin{array}{l}15 \\
(38 \%)\end{array}$ & & & \\
\hline $\begin{array}{l}\text { I would recommend this class } \\
\text { to others } \\
(n=39)\end{array}$ & $\begin{array}{l}25 \\
(64 \%)\end{array}$ & $\begin{array}{l}14 \\
(36 \%)\end{array}$ & & & \\
\hline
\end{tabular}

The third and final component of the survey was comprised of free text questions, asking participants to describe what information they had found most useful and important after attending the pelvic floor class, aspects of the class they most enjoyed, and any suggestions on how the class may be improved. So as to identify information retention, the participants were asked to list their top 3 key take home messages after attending the class. The answers were collated and key themes were identified and are summarised in Table 3. The practical lifestyle changes that participants felt confident they could implement after group attendance were grouped and these are summarised in Table 4.

Table 3. Responses to free text questions - take home messages.

\begin{tabular}{|l|c|l|}
\hline \multicolumn{1}{|c|}{ Top 3 take home messages } & \multicolumn{1}{c|}{ Responses } & \multicolumn{1}{c|}{ Example } \\
\hline $\begin{array}{l}\text { How to correctly/ functionally perform } \\
\text { PFM contraction }\end{array}$ & 12 & $\begin{array}{l}\text { "To remember pelvic floor exercise } \\
\text { when doing jobs like unloading } \\
\text { shopping from (the) boot" }\end{array}$ \\
\hline
\end{tabular}




\begin{tabular}{|c|c|c|}
\hline To start practicing PFM/ dosage & 8 & $\begin{array}{l}\text { "Practice pelvic floor } 3 \times \text { day- } 10 \\
\text { seconds, } 12 \text { repetitions in different } \\
\text { positions" }\end{array}$ \\
\hline Improved understanding & 6 & $\begin{array}{l}\text { "I understand the anatomy related to } \\
\text { the pelvic floor and realise there are } 3 \\
\text { components..." } \\
\text { "Understanding improvement is } \\
\text { possible" } \\
\text { "it was just so interesting and so } \\
\text { relevant" }\end{array}$ \\
\hline Exercise/ lifestyle modification & 5 & $\begin{array}{l}\text { "Knowing I don't have to completely } \\
\text { stop going to the gym" }\end{array}$ \\
\hline Feeling less alone & 5 & $\begin{array}{l}\text { "The percentage of women who have } \\
\text { issues are higher than I thought (this) } \\
\text { makes me feel more normal" } \\
\text { "I feel more hopeful and not so alone" }\end{array}$ \\
\hline Improved toilet habits & 3 & $\begin{array}{l}\text { "Correct toilet position ....avoid } \\
\text { constipation" }\end{array}$ \\
\hline Boat in dock theory explanation & 2 & "Boat in a dock theory" \\
\hline
\end{tabular}

Table 4. Three changes you would put in place after attending the session.

\begin{tabular}{|c|c|c|}
\hline 3 changes & Responses & Example \\
\hline To begin exercise program & 9 & $\begin{array}{l}\text { "Do exercises while driving sitting, } \\
\text { brushing teeth" } \\
\text { "I will include pelvic floor strength in } \\
\text { my daily routine" }\end{array}$ \\
\hline Performing exercises correctly & 8 & $\begin{array}{l}\text { "To do the exercise right" } \\
\text { "To do my exercises different ways" }\end{array}$ \\
\hline Toilet habits & 3 & $\begin{array}{l}\text { "Using a stool during a stool" } \\
\text { "Change sitting position on the toilet" }\end{array}$ \\
\hline Exercise/ lifestyle modification & 3 & $\begin{array}{l}\text { "Avoid high impact exercise" } \\
\text { "Cut down on coffee" } \\
\text { "Drink more water" }\end{array}$ \\
\hline
\end{tabular}

Of the women who attended the group session, $21 / 39(53 \%)$ of the women also went on to attend an individual appointment approximately six weeks after the pelvic floor class with the same physiotherapist. Women attending this were invited to complete a survey consisting of 3 free text questions. The questions asked the women to give their overall impression on the class on reflection, detail any improvements since they attended (and write as a percentage), and list any lifestyle modifications they had made since attending the class. Of those, 19 completed the follow up survey $(90 \%, n=19 / 21)$. When asked to retrospectively reflect on the group session at the individual appointment, the free text responses remained positive.

"The best thing I have done. So far nobody had explained to me what was happening to my body- 3 children...full hysterectomy...no one took the time to explain anything - the pelvic model (the physiotherapist) uses (makes it) much easier to understand everything." 
"The session contained a lot of information that every woman should know, especially for those who have had babies... I feel really positive to have done something to improve my condition."

When asked to comment on whether there had been any improvement in their symptoms 6 weeks after attending the class, 7 women responded yes and 12 women reported that they had not experienced any improvement. When asked to rate their improvement as a percentage, 12 recorded $0 \%, 2$ recorded $20 \%, 4$ reported $50 \%$ and one recorded an improvement of $70 \%$ (mean $=16.3 \%$ standard deviation $=24.3$ ). Eighteen of the 19 respondents had implemented lifestyle modifications or changed their behaviours since attending the class such as "drinking adequate fluid during the day" and felt an increased sense of confidence ("I'm not embarrassed talking about the problems anymore").

\section{DISCUSSION}

Women who attended the pelvic floor class felt less alone, more informed, enjoyed the experience, and were glad they attended. The respondents felt they had received adequate education in relation to anatomy and function of the pelvic floor muscles in a manner that was relevant and appropriate. The responses to the questionnaire indicated that the participants felt they were able to benefit from the whole group experience, and would be able to implement useful and appropriate self management strategies following class attendance. The group format of the session allows for a shared experience which may further enhance treatment outcomes and help to alleviate feelings of being isolated with their symptoms. ${ }^{11}$ There has been shown to be a lack of knowledge of community dwelling women in relation to pelvic floor dysfunction. ${ }^{12}$ By increasing women's awareness, health literacy and knowledge in relation to their pelvic floor dysfunction, this model may be facilitating more informed decision making about their health care and potential treatment options.

In the study, participants felt that they were easily able to attend the session and felt comfortable in a group setting. It has been demonstrated that attending the first session can be a significant hurdle for women due to embarrassment and uncertainty ${ }^{6}$. Grimshaw reported that patients attending their first individual appointment were more relaxed and less apprehensive about an internal examination after attending a preliminary group session. ${ }^{13}$ Anecdotally, the women attending their first individual appointment following the pelvic floor class demonstration good rapport with the clinician as well as a high level of adherence to their prescribed exercised program, however this was not formally measured.

The class appointments were offered to women in a timely manner with $37 / 39$ class appointments being offered within 5 weeks of receiving the referral. Of the 2 patients that waited for longer periods, both were due to an administrative error. Potential barriers for women at this hospital may have included times offered (during working hours) as well as transport and parking issues. Further research focussing on those who did not attend the group session and/or those who attended the group but not a follow up individual consultation would provide additional perspectives not captured in this cohort regarding barriers to attendance.

Previous studies have identified embarrassment about their condition as a potential barrier to women attending a group session. ${ }^{13}$ This was not apparent in the women who attended the but is potentially a contributing factor for the $36 \%$ of women referred to physiotherapy that did not attend a class.

\section{Limitations}

This study is limited by the relatively small sample size and the significant potential for the Hawthorn effect as the physiotherapist conducting the class was also collecting and collating the surveys. This survey is also limited by not considering the views of those who did not attend group session and/or failed to attend their follow up individual appointment, as there may be significant unidentified barriers to attendance in this cohort and the lack of this data collection has the potential to significantly bias the results. Because the questionnaires were issued as a hard copy, many of the respondents did not answer all the questions; thus, the number of responses varied per question. The potential for bias is also a significant limitation of the study as the clinician conducting the class also collected the questionnaires and analysed the data. Due to limited staff resources, having a separate clinician or statistician involved to collect the questionnaire or analyse this this study was not possible.

\section{CONCLUSION}

By providing consistent physiotherapy group sessions for women referred to the physiotherapy department with pelvic floor dysfunction, it is hypothesised that timely and efficient treatment can be commenced prior to an individual physiotherapy appointment. This study adds to the literature the important perspective of the consumer in regards to treatment of pelvic floor dysfunction in a tertiary setting. Women attending the group session found it to be an acceptable, informative, and practical first point of physiotherapy contact. This study serves as a basis for a greater analysis of this method of service delivery. Further research is warranted to ascertain the barriers for those that did not attend the class as this group accounted for over $1 / 3$ of all referrals received. Further research is also necessary to ascertain the reasons those whom attended the class did not attend their follow up individual appointment. By further understanding the barriers to attendance, it may be possible to enhance physiotherapy service delivery in the public hospital setting. Given the current high personal burden and large economic impact of pelvic floor dysfunction in Australia, further research that explores potential strategies to maximise 
efficiency, consumer satisfaction, and most importantly, efficacy of treatment is necessary. In a health care system that requires an economical yet patient centred approach to service delivery, the acceptability of current treatment options to the consumer is paramount. The study has the potential to serve as a foundation for further research into the effectiveness of an education class to be the primary contact of patients in a tertiary hospital.

\section{References}

1. Deloitte Access Economics. The economic impact of incontinence in Australia: Continence Foundation of Australia; 2011 [cited 2019 October 10] Available from; https://www2.deloitte.com/au/en/pages/economics/articles/economicimpact-incontinence-australia

2. Brækken IH, Majida M, Engh ME, Bø K. Can pelvic floor muscle training reverse pelvic organ prolapse and reduce prolapse symptoms? An assessor-blinded, randomized, controlled trial. Am J Obstet Gynecol. 2010;203(170):1-7.

3. Dumoulin C, Hay-Smith J, Jean Habée-Séguin GM, Mercier J. Pelvic floor muscle training versus no treatment, or inactive control treatments, for urinary incontinence in women: A short version Cochrane systematic review with metaanalysis. Neurourol Urodyn 2015;34(4):300-8.

4. Dumoulin C, Cacciari LP, Hay-Smith EJC. Pelvic floor muscle training versus no treatment, or inactive control treatments, for urinary incontinence in women. Cochrane Database of Systematic Reviews. 2018(10).

5. Lamb SE, Pepper J, Lall R, Jorstad-Stein EC, Clark MD, Hill L, et al. Group treatments for sensitive health care problems: a randomised controlled trial of group versus individual physiotherapy sessions for female urinary incontinence. BMC Womens Health. 2009;9:26.

6. Griffiths F, Pepper J, Jorstad-Stein EC, Smith JF, Hill L, Lamb SS. Group versus individual sessions delivered by a physiotherapist for female urinary incontinence: an interview study with women attending group sessions nested within a randomised controlled trial. BMC Womens Health. 2009;9:25.

7. Grimshaw R. An audit of physiotherapy classes for women with pelvic floor dysfunction. Journal of the Association of Chartered Physiotherapists in Women's Health. 2005(96):62-4.

8. Janssen C, Lagro-Janssen A, Felling A. The effects of physiotherapy for female urinary incontinence: individual compared with group treatment. BJU Int. 2001;87(3):201-6.

9. Cook T. Group Treatment of Female Urinary Incontinence: Literature review. Physiotherapy. 2001;87(5):226-34.

10. Australian Commission on Safety and Quality in Health Care (2011), Patient centred care: Improving quality and safety through partnerships with patients and consumers, ACSQHC, Sydney. 2011[cited 2019 Oct 10] Available from; https://www.safetyandquality.gov.au/sites/default/files/migrated/PCC_Paper_August.pdf

11. Cook T. Group Treatment of Female Urinary Incontinence:Literature review. Physiotherapy 2001;87(5):226-34.

12. Fante J. Do Women have Adequate Knowledge about Pelvic Floor Dysfunctions? A Systematic Review. Revista Brasileira de Ginecologia e Obstetrícia. 2019;41:508-19.

13. Aston $B$, Moulder $S$. Is group treatment acceptable in the management of women with pelvic floor dysfunction? Journal of the Association of Chartered Physiotherapists in Women's Health. 2007;101:37-43.

\section{APPENDIX 1 PELVIC FLOOR PHYSIOTHERAPY SESSION EVALUATION}

Group Pelvic Floor Physiotherapy Session Evaluation (WCH)

Date:

Please help us to improve the quality of our Physiotherapy services by completing the evaluation sheet below. Your responses will remain confidential - completion of this form is completely voluntary.

Please circle:

- I attended an: antenatal / gynaecology pelvic floor education session.

Please answer these questions honestly as your feedback is important to us.

Please tick the most applicable box for each statement

\begin{tabular}{|c|l|l|l|l|}
$\begin{array}{c}\text { Strongly } \\
\text { agree }\end{array}$ & Agree & Unsure & Disagree & $\begin{array}{c}\text { Strongly } \\
\text { disagree }\end{array}$ \\
& & & & \\
\hline
\end{tabular}

Please think back to how you felt when you first received the letter inviting you to attend the group session today 


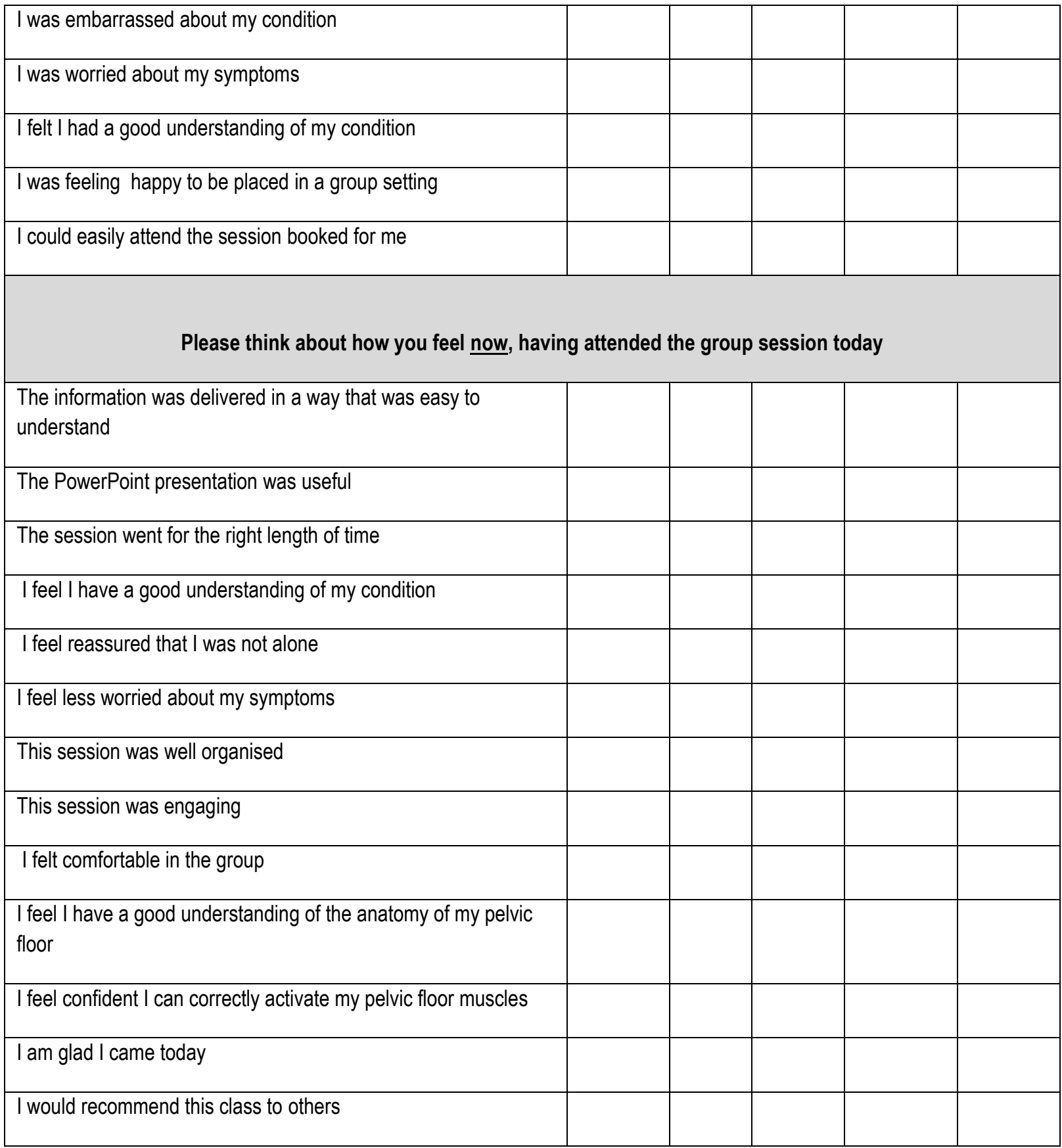

What are the top three take home messages for you after attending this session?

\section{APPENDIX 2 GROUP PELVIC FLOOR PHYSIOTHERAPY FOLLOW-UP SURVEY}

Group Pelvic Floor Physiotherapy Session Evaluation (WCH)

Date:

Please help us to improve the quality of our Physiotherapy services by completing the evaluation sheet below. Your responses will remain confidential - completion of this form is completely voluntary.

I attended gynaecology/antenatal session (please circle)

On reflection, what was your overall impression of the group session? 
Have there been any improvements in your symptoms since attending the session? If yes please give a percentage $0 \%=n o$ change $100 \%=$ completely resolved.

What lifestyle modifications have you made or behaviours have you changed since attending the class

Physiotherapist to complete:

Able to elicit PFM activation $\square$ Yes $\square$ No

ICS Scale: $\square$ Absent $\square$ Weak $\square$ Moderate $\square$ Strong

Have there been any improvements in your symptoms since attending the session? If yes please give a percentage $0 \%=n 0$ change $100 \%=$ completely resolved.

What lifestyle modifications have you made or behaviours have you changed since attending the class? 